\title{
Short communication: Differences in distribution of serotonin receptor subtypes in the mammary gland of sheep, goats, and cows during lactation and involution
}

\author{
A. Suárez-Trujillo, ${ }^{1,2}$ A. Argüello, ${ }^{2}$ M. A. Rivero, ${ }^{3}$ J. Capote, ${ }^{4}$ and N. Castro ${ }^{2 *}$ \\ ${ }^{1}$ Department of Animal Sciences, Purdue University, West Lafayette, IN 47907 \\ ${ }^{2}$ Animal Production and Biotechnology Group, Institute of Animal Health and Food Security, Universidad de Las Palmas de Gran Canaria, \\ Arucas 35413 , Canary Islands, Spain \\ ${ }^{3}$ Division of Histology and Animal Pathology, Institute of Animal Health and Food Security, Universidad de Las Palmas de Gran Canaria, \\ Arucas 35413, Canary Islands, Spain \\ ${ }^{4}$ Instituto Canario de Investigaciones Agrarias, PO Box 60, La Laguna 38297, Canary Islands, Spain
}

\section{ABSTRACT}

Serotonin receptors (5-HTR) are present in the mammary tissue of mouse, humans, cows, and rats. In these species, serotonin is important for the mammary gland function and lactation performance. The mammary gland expression of 5-HTR in small dairy ruminants has yet to be described. In the present study, primer sequences were developed to amplify 5 -HTR (1A, 1D, $1 \mathrm{E}, 1 \mathrm{~B}, 1 \mathrm{~F}, 2 \mathrm{~A}, 2 \mathrm{~B}, 2 \mathrm{C}, 3 \mathrm{a}, 4,5 \mathrm{a}, 6$, and 7) using realtime quantitative PCR for the detection of mRNA expression in mammary tissue of dairy sheep, goats, and cows. The distribution of commonly expressed 5-HTR between the 3 species $(1 \mathrm{~B}, 1 \mathrm{E}, 2 \mathrm{~A}, 2 \mathrm{~B}, 4$, and 7 ) was analyzed in the mammary tissue of late-lactation and dried-off sheep, goats, and cows using immunohistochemical staining. Real-time quantitative PCR analysis showed that the 3 studied species expressed receptors 5-HTR1B, 1E, 2A, 2B, 4, and 7. Goats and sheep expressed 5-HTR1D and 5a; 5-HTR1A and $1 \mathrm{~F}$ were expressed only in sheep. The mammary epithelial cells were positively stained for all the studied receptors by immunohistochemistry (5-HTR1B, 1E, 2A, 2B, 4, and 7). The endothelial cells of blood vessels were positively stained for 5 -HTR1B, 2A, 2B, and 7 in all the species. Additionally, 5-HTR1E was present in cow endothelium. The myoepithelial cells stained positively for 5-HTR1E in all the species, and 5-HTR4 myoepithelial staining was present only in cows and sheep. Between the lactating and dried-off mammary glands, the location of 5 -HTR in the epithelial cells changed from a cytoplasmic reaction in lactating udders to a reaction in the apical region in dry udders. These results showed that the distribution of 5-HTR subtypes in the mammary

Received July 4, 2018.

Accepted November 12, 2018.

*Corresponding author: noemi.castro@ulpgc.es gland of dairy ruminants vary among species, tissue type, and stage of gland development. These findings warrant future studies aimed at understanding whether the differences in 5-HTR subtype expression and location accounts for the differences in milk secretion and lactocyte activity among cows, goats, and sheep.

Key words: ruminants, serotonin receptor, mammary tissue

\section{Short Communication}

Local regulation of the mammary gland physiology depends on several molecules; one of them is serotonin (5-HT). Serotonin functions as a paracrine-autocrine regulator of key physiological functions in several epithelial tissues and systems (Pai and Marshall, 2011; Laporta and Hernandez, 2015). Initial studies conducted by Matsuda et al. (2004) found that 5-HT functions in the mammary epithelial cells (MEC) as a paracrineautocrine inhibitor of lactation. However, subsequent studies support a broader paracrine-autocrine role of serotonin, including the regulation of MEC function and morphology (Pai et al., 2015) and signaling to the bone to increase calcium bioavailability (Hernandez et al., 2012).

The action of 5-HT is elicited through the serotonin receptors (5-HTR). These receptors are divided into 7 classes (5-HTR1 to 5-HTR7), and these classes are divided into 14 subtypes (5-HTR1A, 1B, 1D, 1E, 1F, 2A, 2B, 2C, 3A, 3C, 4, 5a, 6, and 7; Roth, 1994). Immunocytochemical staining of 5-HTR7 in the monolayer cultures of human MEC, MCF10A, showed that it is located on the basolateral membranes (Pai et al., 2015), and mediates tight junction stability in the mouse mammary glands (Pai and Horseman, 2011). Receptor subtype 2 activation is related to the synthesis of parathyroid hormone-related protein (PTHrP) and its release into the blood; PTHrP induces bone resorption, 
resulting in increased calcium in serum (Hernandez et al., 2012; Horseman and Hernandez, 2014; Zang et al., 2018). In dairy cows, the 5-HTR1B genotype is related to the milk production traits (Zhang et al., 2008). Expression of 5-HTR subtypes 1B, 2A, 2B, 4, and 7, using real-time quantitative PCR (RT-qPCR) and in situ hybridization showed that these receptor subtypes are expressed in epithelial, myoepithelial, and vascular endothelial cells of the lactating mammary tissue collected from the dairy cows (Hernandez et al., 2009).

The high interest in understanding small ruminant lactation makes knowledge of the serotoninergic system in ruminants an important topic to explore for a better understanding of their unique mammary gland physiology and for the improvement of their lactation performance. We hypothesized that, in the small ruminants (goats and sheep), several 5-HTR are expressed in the mammary tissue, as has been found in cows, and they are distributed in different cells of the tissue (epithelial, myoepithelial, and endothelial). The objectives of the present work were (1) to develop specific DNA primer sequences to enable the measurement of expression of serotonin receptor subtypes in RNA isolated from sheep, goats, and cows; (2) to describe the mRNA expression of 135 -HTR subtypes by RT-qPCR analysis in the goat and sheep udders; and (3) to locate receptor distribution in the mammary tissue of lactating and dried off sheep, goats, and cows.

For the RT-qPCR analysis, the samples of hypothalamic (positive control) and mammary tissues were obtained from the 3 lactating Holstein cows (Bos taurus), 3 lactating Majorera goats (Capra hircus), and 3 lactating Canarian sheep (Ovis aries) at the slaughterhouse of Gran Canaria, Canary Islands, Spain. All the animals were in late lactation at the time of slaughter. Heads and udders were dissected at the slaughterhouse, and 3 portions of the tissue were obtained from each animal (approximately $25 \mathrm{mg}$ ). The samples were kept in RNAlater (ThermoFisher Scientific, Waltham, MA) at $4^{\circ} \mathrm{C}$ for $24 \mathrm{~h}$. After removing RNAlater, the samples were stored at $-80^{\circ} \mathrm{C}$ until RNA extraction. For the primer sequence development and testing, only the hypothalamic tissue from the 3 species was used. In the previous studies, the hypothalamic tissue has been used as a control tissue due to the presence of all the serotonin receptor subtypes (Hernandez et al., 2009).

For the immunohistochemistry (IHC) analysis, the lactating and dried-off mammary tissue samples were collected from Holstein cows, Majorera goats, and Canarian sheep (3 animals of each species and each physiology period). Additionally, the hypothalamic tissue from Holstein cows, Majorera goats, and Canarian sheep was also collected as a positive control $(\mathrm{n}=3$ of each species). The animals were dried off at least 1 mo before slaughter. All the tissues for IHC were fixed in $4 \%$ buffered formalin for $24 \mathrm{~h}$. Each tissue was evaluated for the signs of pathology using hematoxylin and eosin-stained histology.

The RNA extraction was performed using a combination of TriPure reagent (Hoffmann-La Roche Ltd., Basel, Switzerland) and E.N.Z.A. total RNA kit (Omega Bio-Tek, Norcross, GA) protocols. Sample homogenization and cleaning were performed via the TriPurechloroform method. The RNA extraction protocol was performed following the kit recommendations (http:// omegabiotek.com/store/wp-content/uploads/2013/04/ R6834-Total-RNA-Mini-Kit-I-Combo-Online.pdf). In the last step, each RNA extraction was diluted in 60 $\mu \mathrm{L}$ of RNase-free water.

The RNA concentration, purity, and integrity were determined using a NanoDrop Spectrophotometer (ND-100; Thermo-Scientific). After evaluation, each sample was diluted in RNase-free water to a final concentration of $100 \mathrm{ng} / \mu \mathrm{L}$. Two micrograms of RNA was DNase-treated at $37^{\circ} \mathrm{C}$ for 20 min with $0.5 \mu \mathrm{L}$ of DNase I (2U; \#7326828; BioRad Laboratories S.L., Madrid, Spain). All the samples were loaded in a $1.4 \%$ agarose gel to check RNA integrity. The cDNA synthesis was conducted using iScript cDNA synthesis kit (BioRad Laboratories S.L.). Five microliters of a $100 \mathrm{ng} / \mu \mathrm{L}$ RNA solution was used in a $25-\mu \mathrm{L}$ reaction to obtain a final concentration of $20 \mathrm{ng} / \mu \mathrm{L}$ of cDNA.

The primer sequences for 5 -HTR subtypes $1 \mathrm{~B}, 1 \mathrm{~F}$, $2 \mathrm{~A}, 2 \mathrm{~B}, 2 \mathrm{C}, 4,5 \mathrm{a}$, and 7 and hypoxanthine phosphoribosyltransferase 1 (HPTR1) were obtained from Hernandez et al. (2009) and Reist et al. (2003). The primers for 5 -HTR subtypes $1 \mathrm{~A}, 1 \mathrm{D}, 1 \mathrm{E}, 3 \mathrm{~A}$, and 6 , ribosomal protein S18 (RPS18), ACTB, and GAPDH were designed from Bos taurus and Capra hircus coding DNA sequences (CDS), published at the National Center for Biotechnology Information (https://www .ncbi.nlm.nih.gov/). Primer design was performed using Primer 3 v.0.4.0 (Untergasser et al., 2012). Primer sequences, PCR product length, and primer origins are summarized in Supplemental Table S1 (https://doi .org/10.3168/jds.2018-15328).

For the RT-qPCR analysis, $1 \mu \mathrm{L}$ of cDNA, $10 \mu \mathrm{L}$ of iQ SYBR Green Supermix (BioRad Laboratories S.L.), $0.5 \mu \mathrm{L}$ of forward primer $(10 \mu M), 0.5 \mu \mathrm{L}$ of reverse primer $(10 \mu M)$, and RNase-free water were added for the $25 \mu \mathrm{L}$ of total reaction mix. The analysis was performed using a MyiQ Single Color Real-Time PCR Detection System (BioRad Laboratories S.L.). The following conditions were used for the PCR reaction: $95^{\circ} \mathrm{C}$ for 5 min followed by 40 cycles of $95^{\circ} \mathrm{C}$ for $30 \mathrm{~s} ; 30 \mathrm{~s}$ of the corresponding annealing temperature for each primer (Supplemental Table S2; https://doi .org/10.3168/jds.2018-15328); and $72^{\circ} \mathrm{C}$ for $1 \mathrm{~min}$. The 
HPRT1, GAPDH, RPS18, and ACTB genes were used as housekeeping genes. The efficiency of the control genes was between 90 and 105\%. Resulting gene expression data (cycle threshold values) were calculated using the GAPDH expression as a reference gene (SD spread was $<1.8$ ) and interspecies normalization was performed.

Molecular weights of the PCR amplifications were checked by running them in a $2 \%$ agarose gel. The sequence of each gene in each species was determined to compare the differences between CDS. The sequencing was performed in both the directions of the sequence (forward and reverse) by the Macrogen INC (Amsterdam, the Netherlands) using Sanger method in Applied Biosystems 3730xl DNA Analyzer (ThermoFisher Scientific).

The IHC staining was used to detect 5-HTR in the lactating mammary tissue samples obtained at the same time as samples taken from each species for the RT-qPCR (5-HTR1B, 1E, 2A, 2B, 4, and 7) analysis. The formalin-fixed tissue was paraffin embedded, and $4-\mu \mathrm{m}$ sections were cut. The sections in paraffin were baked on the slides at $37^{\circ} \mathrm{C}$ overnight, deparaffinized in xylene, rehydrated through a graded series of ethanol washes $(100,96$, and 70\%), and rinsed in PBS. Endogenous peroxidases were quenched for 15 min with $3 \%$ hydrogen peroxide in methanol. Antigen-retrieval was performed by incubating the slides in $9.3 \mathrm{mM}$ sodium citrate and $2.0 \mathrm{mM}$ citric acid solution for $10 \mathrm{~min}$ at $95^{\circ} \mathrm{C}$ and $\mathrm{pH} 6$. The slides were allowed to cool at room temperature in sodium citrate and then washed with PBS. The nonspecific binding was blocked by covering the tissue sections with a $10 \%$ solution of nonimmune horse serum (s-2000; Vector Laboratories, Burlingame, $\mathrm{CA}$ ) and incubating for $30 \mathrm{~min}$ at room temperature in a humidified chamber. The excess blocking agent was blotted off the slides. The tissues were incubated overnight at $4^{\circ} \mathrm{C}$ with primary rabbit anti-5-HTR antibodies in PBS. Primary antibodies were diluted 1:75 before use (orb10008 for 5-HTR1B, orb155529 for 5-HTR1E, orb155531 for 5-HTR2A, orb11593 for 5-HTR2B, orb13228 for 5-HTR4, and orb155538 for 5-HTR7; Biorbyt Ltd., Cambridge, UK). Negative controls were incubated with PBS overnight. The slides were washed with PBS and then incubated with biotinylated horse anti-rabbit IgG as secondary antibody (ba-1100; Vector Laboratories) conjugated to horseradish peroxidase. Presence of antibody was visualized using a DAB (3,3'-diaminobenzidine, Sigma-Aldrich, St. Louis, MO) substrate for staining. To highlight the location of myoepithelial cells, calponin IHC was performed in the serial sections. Images of tissue staining were captured at $200 \times$ magnification with a camera mounted to a light microscope. Five random fields from each slide were taken to identify the cell type positive to each 5-HTR.

An animal was accepted as positive for a specific receptor by RT-qPCR analysis if all the 3 portions of mammary tissue were positive; $\leq 2$ positive portions was considered negative expression. In the IHC, an animal was considered positive if the reactivity in a determined cell (epithelial, myoepithelial, or endothelial) was seen in at least 3 different fields.

Primers were designed and validated to measure the mRNA expression of 13 subtypes of 5-HTR in goats, sheep, and cows. All the RT-qPCR products for each 5-HTR showed a similar melting curve and the same molecular weight between species. Further, the sequencing of the amplicons demonstrated that the primers designed for each 5-HTR subtype amplified the same region in the 3 studied species.

The partial CDS of the 13 caprine and ovine 5-HTR subtypes described in this study were deposited and are available for download from NCBI (https://www.ncbi .nlm.nih.gov/; accession numbers for caprine and ovine are shown in Supplemental Table S3, https://doi.org/ 10.3168/jds.2018-15328).

The RT-qPCR analysis of the 13 subtypes of 5-HTR in the lactating mammary tissue of cows, goats, and sheep revealed the expression of 5-HTR1B, 1E, 2A, 2B, 4 , and 7 in the 3 studied species (Table 1). Receptor subtypes 1D and 5a were expressed just in goats and sheep, and 5-HTR1A and $1 \mathrm{~F}$ subtypes were expressed only in sheep. Conversely, 5-HTR2C, 3A, and 6 were not detected in any of the 3 studied species (Table 1 ).

Immunohistochemical analysis of 5-HTR staining in the lactating mammary tissue revealed that 5-HTR1B,

Table 1. Serotonin receptor (5-HTR) subtypes expression in the lactating mammary gland tissue from cows, goats, and sheep by real-time quantitative PCR analysis

\begin{tabular}{|c|c|c|c|c|c|c|c|c|c|c|c|c|c|}
\hline \multirow[b]{2}{*}{ Item } & \multicolumn{13}{|c|}{ 5-HTR subtype } \\
\hline & $1 \mathrm{~A}$ & $1 \mathrm{~B}$ & $1 \mathrm{D}$ & $1 \mathrm{E}$ & $1 \mathrm{~F}$ & $2 \mathrm{~A}$ & $2 \mathrm{~B}$ & $2 \mathrm{C}$ & $3 \mathrm{~A}$ & 4 & $5 \mathrm{a}$ & 6 & 7 \\
\hline Cow & & + & & + & & + & + & & & + & & & + \\
\hline Goat & & + & + & + & & + & + & & & + & + & & + \\
\hline Sheep & + & + & + & + & + & + & + & & & + & + & & + \\
\hline
\end{tabular}

${ }^{1}+$ indicates that the receptor was expressed by real-time quantitative PCR. 
Table 2. Expression of serotonin receptor (5-HTR) subtypes in the lactating mammary gland tissue from cows, goats, and sheep by immunohistochemistry (IHC) ${ }^{1}$

\begin{tabular}{|c|c|c|c|}
\hline Item & $\begin{array}{l}\text { Epithelial } \\
\text { cells }\end{array}$ & $\begin{array}{l}\text { Vascular endothelial } \\
\text { cells }\end{array}$ & $\begin{array}{l}\text { Myoepithelial } \\
\text { cells }\end{array}$ \\
\hline \multicolumn{4}{|c|}{ 5-HTR1B } \\
\hline Cow & + & + & \\
\hline Goat & + & + & \\
\hline Sheep & + & + & \\
\hline \multicolumn{4}{|c|}{ 5-HTR1E } \\
\hline Cow & + & + & + \\
\hline Goat & + & & + \\
\hline Sheep & + & & + \\
\hline \multicolumn{4}{|c|}{ 5-HTR2A } \\
\hline Cow & + & + & \\
\hline Goat & + & + & \\
\hline Sheep & + & + & \\
\hline \multicolumn{4}{|c|}{ 5-HTR2B } \\
\hline Cow & + & + & \\
\hline Goat & + & + & \\
\hline Sheep & + & + & \\
\hline \multicolumn{4}{|c|}{ 5-HTR4 } \\
\hline Cow & + & & + \\
\hline Goat & + & & \\
\hline Sheep & + & & + \\
\hline \multicolumn{4}{|l|}{ 5-HTR7 } \\
\hline Cow & + & + & \\
\hline Goat & + & + & \\
\hline Sheep & + & + & \\
\hline
\end{tabular}

$1 \mathrm{E}, 2 \mathrm{~A}, 2 \mathrm{~B}, 4$, and 7 were expressed in the epithelial cells of cows, goats, and sheep (Table 2 and Supplemental Figures S1-S6; https://doi.org/10.3168/jds.2018 -15328). The vascular endothelial cells were positively stained for 5-HTR1B, 2A, 2B, and 7 in all 3 species studied; however, only endothelial cells in the mammary tissue from cows stained positively for 5 -HTR1E. The 5-HTR1E staining was also detected in the myoepithelial cells across all the 3 species. Additionally, myoepithelial cells were positively stained in cows and sheep for 5-HTR4.

The reaction for all the studied receptors by IHC had a cytoplasmic disposition in the lactating MEC. The mammary tissue samples collected from dry animals had higher infiltration of connective tissue and a lower proportion of alveoli relative to the lactating counterparts. The alveolar structures were also less differentiated, as evident in the smaller luminal area. The epithelial cells in udders from dry animals showed staining reaction for all 5-HTR subtypes in the apical region of the lactocyte.

The 5 -HTR subtypes $1 \mathrm{~B}, 2 \mathrm{~A}, 2 \mathrm{~B}, 4$, and 7 were previously detected by $\mathrm{RT}-\mathrm{qPCR}$ in the cow mammary tissue by Hernandez et al. (2009). The present study reports that these 5-HTR subtypes are also expressed in the lactating mammary tissue from the goats and sheep. Additionally, 5-HTR subtype $1 \mathrm{E}$ has been detected in the 3 studied species. Together, these results demonstrated that the expression of these receptors is conserved across the 3 species. In cows, the 5-HTR1B genotype has been associated with the milk production traits (Zhang et al., 2008). Demonstration of the expression of 5-HTR1B in the lactating mammary tissue from the goats and sheep warrants further investigation of whether similar polymorphisms account for the differences in milk production among and between these species. Hernandez et al. (2012) also demonstrated that 5 -HTR $2 \mathrm{~A}$ and $2 \mathrm{~B}$ were expressed in the mammary tissue from mice, cows, and humans. The 5-HTR2 expression was related to the production of $\mathrm{PTHrP}$ in the mammary during lactation. The function of 5 -HT as a regulator of calcium homeostasis through receptors $2 \mathrm{~A}$ and $2 \mathrm{~B}$ might be conserved across other mammals. We also found 5-HTR7 to be expressed in the 3 species studied. 5-HTR7 regulates the stability of tight junctions among alveolar cells (Stull et al., 2007) and milk protein synthesis (Hernandez et al., 2009). The critical role of 5-HTR7 in the mammary gland function of other species suggests that it may play a fundamental role in regulating the mammary physiology in sheep and goats.

We found the distribution of the different 5-HTR in the cow mammary tissue by IHC to be consistent with that described by Hernandez et al. (2009) using in situ hybridization. Receptor subtypes 1B, 2A, 2B, and 7 found in the endothelial cells may function as 
regulators of the blood flow in the mammary gland. In the myoepithelial cells, receptor $1 \mathrm{E}$ was positively stained in the 3 species and subtype 4 only in cows and sheep. Serotonin has been described as a molecule that increases the contractibility of the myoepithelial cells (Oguro et al., 1982). To reduce the pressure produced by milk accumulation, high levels of 5 -HT could bind its receptors on the myoepithelial cells and produce alveoli contraction, moving the milk down into the cistern.

This is the first report of 5-HTR expression and distribution in the mammary tissue of lactating and driedoff udders of goats and sheep. Previously, Matsuda et al. (2004) demonstrated that TPH1, which is required for 5-HT synthesis, is expressed in different mammary developmental stages in mouse, but the presence of 5-HTR in the mammary glands during involution has not been previously described. The cytoplasmic staining for receptors in MEC in situ is contrary to the basolateral membrane staining for 5-HTR7 in the MCF10A cells reported by Stull et al. (2007). In the glands of dried-off animals, we found that receptor distribution was primarily in the apical side of the cells. After involution, the secretory tissue glands of dried-off dairy animals are in a steady state with low metabolic activity; thus, mammary epithelial turnover regulates lactation and mammary-epithelial homeostasis plays a less important role.

In conclusion, small ruminants express 5-HTR. The common 5-HTR subtypes between small ruminants and cows include 5-HTR 1B, 2A, 2B, 4, and 7, whereas some 5-HTR were expressed exclusively in sheep and goats. All the common receptor subtypes in the 3 studied species were positively stained in the epithelial cells, suggesting that serotonin, as in dairy cows, plays an important role in the regulation of goat and sheep lactation. Further studies must be performed to elucidate 5 -HT function in small ruminant mammary glands, to explain the differences between goat and sheep lactation and milk secretion compared with cows.

\section{ACKNOWLEDGMENTS}

This work was supported by an FPU 12/06079 Scholarship from Ministry of Education, Culture and Sports of the Spanish Government (Madrid, Spain). The authors appreciate the assistance of the veterinary service at the slaughterhouse of Gran Canaria (Canary
Islands, Spain). Finally, the authors thank Theresa M. Casey (Animal Sciences Department, Purdue University, West Lafayette, IN) for review of the English style in this article.

\section{REFERENCES}

Hernandez, L. L., K. A. Gregerson, and N. D. Horseman. 2012. Mammary gland serotonin regulates parathyroid hormone-related protein and other bone-related signals. Am. J. Physiol. Endocrinol. Metab. 302:E1009-E1015.

Hernandez, L. L., S. W. Limesand, J. L. Collier, N. D. Horseman, and R. J. Collier. 2009. The bovine mammary gland expresses multiple functional isoforms of serotonin receptors. J. Endocrinol. 203:123-131.

Horseman, N. D., and L. L. Hernandez. 2014. New concepts of breast cell communication to bone. Trends Endocrinol. Metab. 25:34-41.

Laporta, J., and L. L. Hernandez. 2015. Serotonin receptor expression is dynamic in the liver during the transition period in Holstein dairy cows. Domest. Anim. Endocrinol. 51:65-73.

Matsuda, M., T. Imaoka, A. J. Vomachka, G. A. Gudelsky, Z. Y. Hou, M. Mistry, J. P. Bailey, K. M. Nieport, D. J. Walther, M. Bader, and N. D. Horseman. 2004. Serotonin regulates mammary gland development via an autocrine-paracrine loop. Dev. Cell 6:193-203.

Oguro, K., H. Hashimoto, and M. Nakashima. 1982. Pharmacological effects of several drugs on the myoepithelium and vascular smooth-muscle of the lactating mammary-gland in goats. Arch. Int. Pharmacodyn. Ther. 256:108-122.

Pai, V. P., L. L. Hernandez, M. A. Stull, and N. D. Horseman. 2015. The type 7 serotonin receptor, 5 -HT 7 , is essential in the mammary gland for regulation of mammary epithelial structure and function. BioMed Res. Int. 2015:364746. https://doi.org/10.1155/ $2015 / 364746$.

Pai, V. P., and N. D. Horseman. 2011. Multiple cellular responses to serotonin contribute to epithelial homeostasis. PLoS One 6:e17028.

Pai, V. P., and A. M. Marshall. 2011. Intraluminal volume homeostasis: A common sertonergic mechanism among diverse epithelia. Commun. Integr. Biol. 4:532-537.

Reist, M., M. W. Pfaffl, C. Morel, M. Meylan, G. Hirsbrunner, J. W. Blum, and A. Steiner. 2003. Quantitative mRNA analysis of eight bovine 5-HT receptor subtypes in brain, abomasum, and intestine by real-time RT-PCR. J. Recept. Signal Transduct. Res. 23:271-287.

Roth, B. L. 1994. Multiple serotonin receptors: Clinical and experimental aspects. Ann. Clin. Psychiatry 6:67-78.

Stull, M. A., V. Pai, A. J. Vomachka, A. M. Marshall, G. A. Jacob, and N. D. Horseman. 2007. Mammary gland homeostasis employs serotonergic regulation of epithelial tight junctions. Proc. Natl. Acad. Sci. USA 104:16708-16713.

Untergasser, A., I. Cutcutache, T. Koressaar, J. Ye, B. C. Faircloth, M. Remm, and S. G. Rozen. 2012. Primer3-new capabilities and interfaces. Nucleic Acids Res. 40:e115.

Zang, W. J., H. Li, Z. F. Zhang, R. GuZhen, Y. Z. CuoMu, D. K. Zhang, J. Luo, J. J. Loor, and H. L. Zheng. 2018. Serotnin induces parathyroid hormone-related protein in goat mammary gland. J. Anim. Sci. 96:1010-1016.

Zhang, C. L., H. Chen, Y. H. Wang, R. F. Zhang, X. Y. Lan, C. Z. Lei, L. Zhang, A. L. Zhang, and S. R. Hu. 2008. Serotonin receptor 1B (5-HTR1B) genotype associated with milk production traits in cattle. Res. Vet. Sci. 85:265-268. 